\title{
Endobronchial Obstruction
}

National Cancer Institute

\section{Source}

National Cancer Institute. Endobronchial Obstruction. NCI Thesaurus. Code C156466.

Partial or complete blockage of the bronchial lumen by a pathological process that occurs within the bronchus. 